\title{
HIV-1 Tat induces DNMT over-expression through microRNA dysregulation in HIV-related non Hodgkin lymphomas
}

Anna Luzzi ${ }^{1}$, Federica Morettini ${ }^{1}$, Sara Gazaneo ${ }^{1}$, Lucia Mundo ${ }^{1}$, Anna Onnis${ }^{1}$, Susanna Mannucci' Emily A Rogena ${ }^{1,2}$, Cristiana Bellan ${ }^{1}$, Lorenzo Leoncini ${ }^{1}$ and Giulia De Falco ${ }^{1,3^{*}}$

\begin{abstract}
Background: A close association between HIV infection and the development of cancer exists. Although the advent of highly active antiretroviral therapy has changed the epidemiology of AIDS-associated malignancies, a better understanding on how HIV can induce malignant transformation will help the development of novel therapeutic agents.
\end{abstract}

Methods: HIV has been reported to induce the expression of DNMT1 in vitro, but still no information is available about the mechanisms regulating DNMT expression in HIV-related B-cell lymphomas.

In this paper, we investigated the expression of DNMT family members (DNMT1, DNMT3a/b) in primary cases of aggressive B-cell lymphomas of HIV-positive subjects.

Results: Our results confirmed the activation of DNMT1 by HIV in vivo, and reported for the first time a marked up-regulation of DNMT3a and DNMT3b in HIV-positive aggressive B-cell lymphomas. DNMT up-regulation in HIV-positive tumors correlated with down-regulation of specific microRNAs, as the miR29 family, the miR148-152 cluster, known to regulate their expression. Literature reports the activation of DNMTs by the human polyomavirus BKV large T-antigen and adenovirus E1a, through the pRb/E2F pathway. We have previously demonstrated that the HIV Tat protein is able to bind to the pocket proteins and to inactivate their oncosuppressive properties, resulting in uncontrolled cell proliferation. Therefore, we focused on the role of Tat, due to its capability to be released from infected cells and to dysregulate uninfected ones, using an in vitro model in which Tat was ectopically expressed in B-cells.

Conclusions: Our findings demonstrated that the ectopic expression of Tat was per se sufficient to determine DNMT up-regulation, based on microRNA down-regulation, and that this results in aberrant hypermethylation of target genes and microRNAs.

These results point at a direct role for Tat in participating in uninfected B-cell lymphomagenesis, through dysregulation of the epigenetical control of gene expression.

Keywords: HIV, Aggressive B-cell lymphomas, microRNAs, DNMTs, Tat

\footnotetext{
* Correspondence: giulia.defalco@qmul.ac.uk

'Department of Medical Biotechnologies, University of Siena, Siena, Italy

${ }^{3}$ School of Biological and Chemical Sciences, Queen Mary University of London, London, UK

Full list of author information is available at the end of the article
} 


\section{Background}

A close association between Human Immunodeficiency Virus (HIV) infection and the development of a number of cancers, NHL being the second most common, has been described. Interestingly, AIDS-associated lymphomas are of B-lymphoid origin in at least $95 \%$ of all cases described despite the fact that HIV infects T-lymphocytes [1], raising the question whether HIV may have a direct role in B-cell lymphomagenesis. To date, there are no clear answers to explain how HIV leads to transformation, even though several events have been proposed as cofactors in HIV-related tumorigenesis. The frequencies of different subpopulations of B-cells have been reported altered in the presence of HIV Reviewed in [2]. These changes include increased frequency of activated and terminally differentiated B-cells expressing low levels of $\mathrm{CD} 21$ that have been associated with ongoing viral replication [3,4], a decreased frequency of memory B-cells that is not reversed by antiretroviral therapy [5], and an increased frequency of immature/transitional B-cells that has been associated with $\mathrm{CD} 4^{+} \mathrm{T}$-cell lymphopenia [6-8]. Although there is no indication of a direct role for the virus in the B-cell transformation, lymphadenopathy, polyclonal B-cell proliferation, and even lymphoma may precede overt compromise of T-cell immunity $[9,10]$. In addition, changes in the microenvironment of the host cells have been recorded following HIV infection [11], as well as chronic immune activation and dysfunctional cytokine production that have been described throughout all stages of HIV-1 infection [12].

In addition to these indirect effects, HIV may directly contribute to B-cell transformation through its encoded proteins and/or viral microRNAs (miRNAs), using which it can disturb gene and miRNA expression in host cells [13]. It is noteworthy that most transformed B-cells do not contain the virus, therefore some other mechanisms and/or viral factors may contribute to transformation. In particular, several findings support an oncogenic role of the HIV-1 Tat protein, which is essential for viral gene expression and virus production [14-16]. A soluble, biologically active form of Tat is released by HIV-infected cells, taken up and translocated to the nucleus by neighbouring uninfected ones [17-19], and may directly contribute to B-cell abnormalities in HIV-positive patients [20]. We have previously demonstrated that B-cell lymphomas of HIV-infected individuals may be positively stained by an anti-Tat antibody [21]. Therefore it is reasonable to hypothesize that the endocytosed Tat, released from infected cells, may then exert its pleiotropic activities in uninfected B-cells. Tat has been reported to modulate the expression of several cellular genes, including cytokines and their receptors [22-24]. In particular, the ability of Tat to increase the expression of interleukins- 6 (IL-6) and 10 (IL-10) $[25,26]$, which in turn promote B-cell stimulation, and the evidence that about $30 \%$ of Tat-transgenic mice develop B-cell lymphomas [27], suggest that Tat might play a role in the pathogenesis of HIV-related B-lymphomas. In particular, IL- 6 has been reported to induce the overexpression of the DNA Methyltransferase 1 (DNMT1), which has a key role in the maintenance of DNA methylation, and epigenetically regulate the expression of several genes, in liver cancer through miRNA dysregulation, which correlates with increased genomic methylation [28]. Interestingly, HIV has been reported to induce the expression of DNMT1 $[29,30]$ in vitro, though there is no evidence that this can be exerted through IL-6 in HIV-positive individuals, although serum IL-6 is significantly elevated in $\mathrm{HIV}^{+}$subjects who develop aggressive B-cell lymphomas [31]. In addition, induction of DNMT aberrant activity has been reported by several human viruses through the $\mathrm{pRb} /$ E2F pathway [32]. In particular, this occurs through the interaction of viral products with the RB proteins and their consequent inactivation [33-37]. Noteworthy, we have previously reported the physical interaction of Tat with the pocket proteins, which results in their inactivation and inhibition of their growth regulatory properties $[21,38]$. This suggests that Tat may contribute to DNMT aberrant expression in HIV-positive subjects.

In this paper we have investigated the possible mechanisms used by HIV to induce DNMT over-expression. In particular, we have analyzed whether DNMT induction by HIV could depend on specific miRNA dysregulation, as reported in liver cancer $[28,39]$. Our results show that DNMT1, DNMT3a/b are up-regulated in B-cell lymphomas, and that this relies on down-regulation of specific miRNAs. To assess the possible contribution of Tat, we used an in vitro model, in which Tat was ectopically expressed in uninfected B-cells. The ectopic expression of Tat resulted in the up-regulation of DNMT1, DNMT3a/b based on down-regulation of specific miRNAs, in accordance to what we observed in HIV-positive primary tumors.

DNMT over-expression may result in altered methylation pattern of genes and/or microRNAs, therefore we investigated whether it may affect the expression of genes frequently reported to be inactivated by hypermethylation, as INK4/p16, TP53 and RB1. In addition, we tested whether down-regulation of DNMT-regulating miRNAs detected in our cell model was possibly dependent on hypermethylation as well, in a feedback-loop mechanism fashion. Here we show that the ectopic expression of Tat determines an altered methylation pattern of INK4/p16 and of specific miRNAs, this finding being also confirmed in HIV-positive tumors.

These results point out at the possible role for Tat in participating in B-cell lymphomagenesis in uninfected cells, through dysregulation of the host cell miRNA machinery and of the epigenetic control of gene expression, 
and provide novel information to the molecular mechanisms of B-cell lymphomagenesis in HIV-infected individuals.

\section{Methods}

\section{Ethics statement}

The Institutional Review Board of the University of Siena (Italy) and the Ethics and Research Committee of the University of Nairobi (Kenya) gave ethics approval for this study. Informed written consent was obtained in all cases.

\section{Case selection and immunophenotype}

For this study aggressive 30 formalin-fixed paraffinembedded (FFPE) cases of HIV-positive B-cell lymphoma (DLBCL, BL) and 30 formalin-fixed paraffin-embedded cases of HIV-negative B-cell lymphoma (DLBCL, BL) collected at the Department of Pathology, Nairobi Hospital, Kenya and the Department of Human Pathology and Oncology, University of Siena, Italy, have been used. Cases were reviewed by expert pathologists $(B C, L L)$ and diagnoses were confirmed by morphology on histological slides stained with HE, Giemsa and by immunophenotyping, according to the Word Health Organization (WHO) [1]. 5 reactive lymph nodes were used as negative controls. Immunohistochemical studies were performed on representative paraffin sections from each case using microwave pre-treatment of slides for antigen retrieval, as previously reported [40]. A large panel of antibodies recognizing formalin-resistant epitopes of the various antigens was applied (Table 1). The presence of the Epstein-Barr virus (EBV) was assessed by in situ hybridization for EBERs as described [41]. HIV-positive cases were mostly positive for EBV.

Table 1 List of the antibodies used for immunohistochemistry

\begin{tabular}{lll}
\hline Primary antibody & Dilution & Company \\
\hline DNMT-1 & $1: 50$ & BD \\
DNMT3A & $1: 50$ & Abcam \\
TAT & $1: 100$ & Abcam \\
BCL6 & $1: 30$ & Dako \\
BCL2 & $1: 150$ & Dako \\
CD20 & $1: 150$ & NeoMarkers \\
IgM & $1: 10000$ & Dako \\
CD30 & $1: 50$ & NeoMarkers \\
CD10 & $1: 20$ & NeoMarkers \\
CD79 & $1: 50$ & NeoMarkers \\
Irf-4 & $1: 50$ & Dako \\
CD38 & $1: 100$ & Dako \\
\hline
\end{tabular}

\section{PCR for detection of HIV infection}

All of the HIV-positive lymphomas were tested for HIV genome presence. A fragment of the HIV-1 DNA was amplified by nested PCR using the lentivirus universal primer pair UNIPOL1/2 as outer primers ( 25 cycles) and the degenerate primers UNIPOL3 (50-GAAACAGGAMRRG AGACAGC-30) and UNIPOL4 (50-TTCATDGMTTCC ACTACTCCTTG-30) as inner primers (30 cycles) [42]. This nested primer set, when used at low-stringency annealing, specifically amplifies all HIV-1 and HIV-2 pol sequences known to date. PCR products were visualized on agarose gels and the specificity of the products was confirmed by direct sequencing.

\section{Computational analysis}

miRNAs predicted to regulate the expression of DNMT1 (hsa-miR-130a, hsa-miR-130b, hsa-miR-148a, hsa-miR148b, hsa-miR-152, hsa-miR-301) and DNMT3a/b (hsamiR-29a, hsa-miR-29b and hsa-miR-29c, hsa-miR-148a, hsa-miR-148b) were identified by computational analysis, using web-available resources (Mirnaviewer, PicTar, Tarbase [43] and miRBase [44]; mirnaviewer is available at http://cbio.mskcc.org/mirnaviewer; PicTar is a project of the Rajewsky lab at NYU's Center for Comparative Functional Genomics and the Max Delbruck Centrum, Berlin). Among the many available by bioinformatics predictions, these specific miRNAs were selected for this study as regulation of DNMTs by these miRNAs through direct mRNA binding has been previously proved $[45,46]$.

\section{MiRNA extraction}

Extraction of miRNAs from FFPE sections of primary tumors and reactive lymph nodes was performed using the miRNA easy FFPE kit (Qiagen, Carlsbad, CA), following manufacturer's instructions. Quality and purity of RNA were assessed by spectrophotometric read using Nanodrop (Thermo Scientific, Wilmington, DE) and by Agilent Bioanalyzer (Agilent Technologies, Santa Clara, CA).

\section{Analysis of miRNA expression}

MiRNA expression was analyzed by RT-qPCR as previously described [41]. For each sample, $10 \mathrm{ng}$ of total RNA were reverse transcribed. Real-time PCR was performed using Taqman probes specific for each miRNA (hsa-miR130a, hsa-miR-130b, hsa-miR-148a, hsa-miR-148b, hsamiR-152, hsa-miR-301, hsa-miR-29a, hsa-miR-29b and hsa-miR-29c), and for RNU43, used as an endogenous control (Applied Biosystems, Applera, Italy). Amount and quality of RNA were evaluated measuring the OD at $260 \mathrm{~nm}$, the 260/230 and the 260/280 ratios by Nanodrop (Celbio, Italy). 


\section{Gene expression analysis}

Relative quantification of gene expression for Cyclin $A$, DNMT1, DNMT3a, DNMT3b, INK4/p16, RB1 and TP53 was also carried out by Real-time PCR using FluoCycle SYBR green (Euroclone, Celbio, Italy) according to manufacturer's instructions. HPRT was used as housekeeping gene. The complete list of primers used for qPCR is provided in Table 2. Differences in gene expression were calculated using the $\Delta \Delta \mathrm{Ct}$ method [47].

\section{Recombinant Tat}

The recombinant Tat HIV-1 IIIB (aa 1-86) from Dr J Raina was obtained through the EU Programme EVA/ MRC Centralised Facility for AIDS Reagents, NIBSC, UK (Grant numbers QLK2-CT-1999-00609 and GP828102). The stock solution was diluted in saline citrate buffer as recommended, and aliquots were stored at $-80^{\circ} \mathrm{C}$ until use. The concentration of endotoxin was below 0.01 endotoxin unit (EU)/mg of protein. Extracellular Tat $(50 \mathrm{ng} / \mathrm{ml})$ was added to the medium culture of cells for $48 \mathrm{~h}$. Cells grown in the absence of Tat were used as a control.

\section{Ectopic expression of Tat in vitro}

Tat ectopic expression was either obtained through exposure to recombinant Tat or through transient and stable transfections, by nucleofection. A Burkitt lymphomaderived EBV-negative cell line (Ramos) was used to perform the in vitro experiments. Briefly, cells were cultured in RPMI supplemented with $10 \% \mathrm{FBS}, 1 \%$ L-glutamine, penicillin/streptomycin, with $5 \% \mathrm{CO}_{2}$, at $37^{\circ} \mathrm{C}$. The recombinant Tat was used as previously described [38]. Cells

\section{Table 2 Primers used for qPCR}

\begin{tabular}{ll}
\hline Gene & Primer sequence \\
\hline CYCLIN A-FORWARD & 5'-AGG CTT CAA AGT ACC TGT GTG-3' \\
CYCLIN A-REVERSE & 5'-TTG ATC CCA CGT GCA GAA G-3' \\
DNMT1-FORWARD & 5'-CGACTACATCAAAGGCAGCAACCTG-3' \\
DNMT1-REVERSE & 5'-TGGAGTGGACTTGTGGGTGTTCTC-3' \\
DNMT3A-FORWARD & 5'-TAT TGA TGA GCG CAC AAG AGA GC-3' \\
DNMT3A-REVERSE & 5'-GGG TGT TCC AGG GTA ACA TTG AG-3' \\
DNMT3b-FORWARD & 5'-GGC AAG TTC TCC GAG GTC TCTG-3' \\
DNMT3b-REVERSE & 5'-TGG TAC ATG GCT TTT CGA TAG GA-3' \\
RB1 FORWARD & 5'-CAC CAA TAC CTC ACA TTC CTC-3' \\
RB1 REVERSE & 5'-TTC TCA GAA GTC CCG AAT G-3' \\
TP53 FORWARD & 5'-CCA TCC TCA CCA TCA TCA C-3' \\
TP53 REVERSE & 5'-GGC AGT GCT CGC TTA GTG G-3' \\
INK4/P16 FORWARD & 5'-GGA AGG TCC CTC AGA CAT C-3' \\
INK4/p16 REVERSE & 5'-GCA GTT GTG GCC CTG TAG-3' \\
\hline
\end{tabular}

Primers for CYCLIN A amplified a region of $105 \mathrm{bp}$; Primers for DNMT1 amplified a region of $88 \mathrm{bp}$; Primers for DNMT3a amplified a region of $68 \mathrm{bp}$; Primers for DNMT3b amplified a region of $68 \mathrm{bp}$; Primers for RB1 amplified a region of $152 \mathrm{bp}$; Primers for TP53 amplified a region of $140 \mathrm{bp}$; Primers for INK4/p16 amplified a region of $67 \mathrm{bp}$. grown in the absence of Tat were used as a negative control. Transient and stable transfections were performed by nucleofection, using an Amaxa apparatus, program T16 and solution T (Amaxa, Cologne, Germany). A transfection efficiency of $45 \%$ was obtained, as assessed by FACS analysis for a GFP reporter. Cells $\left(2 \times 10^{6}\right)$ were transfected with $10 \mu \mathrm{g}$ of pCDNA3-Tat [38], using the empty vector as negative control. In addition, a stable Tat-transfected Ramos cell line was obtained by antibiotic selection with G-418, at the concentration of $2 \mathrm{mg} / \mathrm{ml}$.

\section{Cell proliferation}

The effect of Tat on cell proliferation was assessed as previously described [40]. Briefly, cell counts were established by Tripan blue staining and the possible effect of Tat on the cell cycle was monitored by analysis of Cyclin A expression, used as a specific S-phase marker, by RTqPCR, as described above. In addition, proliferation was also monitored following transfections with miRNA mimics and inhibitors (see below). Statistical significance was assessed by the analysis of variance (ANOVA) test.

\section{miRNA nucleofection}

To assess the regulation of the target genes by the predicted miRNAs in our cell model, modulation of the endogenous miRNAs was obtained by synthetic miRNAs and inhibitors (Dharmacon, Celbio, Milan, Italy), through nucleofection, followed by detection of the expression of the genes of interest. Briefly, cells were split the day before nucleofection and $5 \times 10^{6}$ cells were transfected with different concentrations of either the miRNA mimic or inhibitor (10 nM, $50 \mathrm{nM}$ or $100 \mathrm{nM}$ ), to assess the best doseresponse concentration. Negative control of mimics and inhibitors (NC, NCI, respectively) were used at the $10 \mathrm{nM}$ concentration (Dharmacon, Euroclone, Milan, Italy). As the selected miRNAs regulating DNMT1 map in clusters, we used one mimic/inhibitor for each cluster. In particular, mimics and inhibitors of hsa-miR130a, hsa-miR152 and hsa-miR29 were used to modulate the endogenous expression of DNMT1 and DNMT3a/b, respectively (all from Dharmacon, Euroclone, Milan, Italy). To analyze the downstream DNMT modulation, mimics and inhibitors were used at the concentration which gave the best effect. RNA was extracted 24 hours after nucleofection and both gene expression for DNMTs and miRNA expression were checked by Real-Time RT-PCR, as previously described.

\section{Western blotting}

Cells pellets were lysed on ice for in EBC buffer (50 nM Tris- $\mathrm{HCl} \mathrm{pH}$ 8.0, $130 \mathrm{mM} \mathrm{NaCl}, 1 \%$ Triton X-100, 0.1\% SDS) supplemented with protease inhibitor cocktail (Sigma, Milan-Italy). Cell lysates were separated by $10 \%$ SDS-PAGE gel followed by transfer to Hybond ECL nitrocellulose membrane (GE Healthcare, Milan, Italy). 
Western blotting was made using anti-DNMT1 (1:400, BD, NJ USA), anti-DNMT3a (1:250, Abcam, UK) and anti-actin (1:1000, BD, NJ USA). Secondary antibodies conjugated with HRP were used at a dilution of 1:5000 and the reaction was revealed using the ECL Western Blotting Kit (Promega, Milan-Italy) according to the manufacturer's instructions.

\section{DNA extraction and methylation assay}

FFPE section $(10 \mu \mathrm{m})$ of 5 cases of DLBCL HIV-positive, 5 cases of DLBCL HIV-negative and 2 reactive lymph nodes were deparaffinized with xylene and DNA extraction was performed with NucleoSpin kit (MachereyNagel), according to manufacturer's instructions. Amount and quality of DNA were evaluated measuring the OD at $260 \mathrm{~nm}$, the $260 / 230$ and the 260/280 ratios by Nanodrop (Celbio, Italy). DNA quality control PCR was also performed as previously described (21). $500 \mathrm{ng}$ of DNA of each case were modified by bisulfite (EZ DNA Methylation-Gold kit ZYMO RESEARCH) according to manufacturer's instructions. Approximately $100 \mathrm{ng}$ of converted DNA were amplified using methylation specific primers (MSP) or bisulfite sequencing primers (BSP). Primer sequences for MSP are provided in Table 3. PCR products were separated on a $2 \%$ agarose gel to confirm size. For methylation assay primers were designed using the MethPrimer (MethPrimer - Li Lab, UCSF www.urogene.org/methprimer/index1.html). For some microRNAs the software did not identify any CpG islands (hsa-miR130b, hsa-miR148b, hsa-miR301, hsa-miR-29a, hsa-miR-29b, hsa-miR-29c), therefore methylation was assessed for miRNAs containing CpG islands. In some cases, designed primers amplified a product size which was too long to be amplified in our primary tumors, according to the DNA quality control, and therefore they were discarded. Methylation was

\section{Table 3 Primer sequences for MSP}

\begin{tabular}{ll}
\hline Gene & Primer sequence \\
\hline INK4/p16 U FORWARD & 5'-TTA TTA GAG GGT GGG GTG GAT TGT-3' \\
INK4/p16 U REVERSE & 5'-CAA CCC CAA ACC ACA ACC ATA A-3' \\
INK4/p16 M FORWARD & 5'-TTA TTA GAG GGT GGG GCG GAT CGC-3' \\
INK4/p16 M REVERSE & 5'-GAC CCC GAA CCG CGA CCG TAA-3' \\
TP53 U FORWARD & 5'-TTT TTT AGG TAG TTT TTG GTT TTG T-3' \\
TP53 U REVERSE & 5'-ACC AAA CCT CTC AAA TTA CAA CAA T-3' \\
TP53 M FORWARD & 5'-ATT TTT TTA GGT AGT TTT CGG TTT C-3' \\
TP53 M REVERSE & 5'-GAA CCT CTC AAA TTA CGA CGA T-3'
\end{tabular}

Primers for INK4/p16 unmethylated (U) amplified a region of $151 \mathrm{bp}$, primers for INK4/p16 methyled (M) amplified a region of $150 \mathrm{bp}$; primers for TP53 unmethylated amplified a region of $134 \mathrm{bp}$, primers for TP53 methylated amplified a region of $133 \mathrm{bp}$. therefore checked using different approaches, collectively MSP and BSP, followed by direct sequencing, and treatment with 5-Aza. Methylation assay was carried out either in primary tumors or Tat-transfected cell lines by MSP and BSP, according to the product size, and by 5 -Aza treatment in cell lines (see below). Primer sequences are reported in Table 4.

\section{Treatment with 5-aza-2-deoxycitidine}

To test whether miRNA down-regulation in HIVpositive tumors was possibly due to hypermethylation following DNMT over-expression, Ramos cells (either transfected or not with a vector coding for Tat) were treated with $1 \mu \mathrm{M}$ 5-aza-2-deoxycitidine as reported [41] and relative quantification of miRNAs was made by RTqPCR two days after treatment, as previously described.

\section{Results}

HIV induces the aberrant expression of DNMTs

HIV is reported to induce the expression of DNMT1 in vitro [29,30], though no information is available about its effect on DNMT3a/b, and about their expression in HIV-positive B-cell lymphomas. Therefore relative expression of DNMTs was checked in HIV-positive and HIVnegative primary tumors of aggressive B-cell lymphomas vs. reactive lymph nodes, both by RT-qPCR (Figure 1a) and immunohistochemistry (Figure 1b-e), respectively. DNMT1, DNMT3a/b were found up-regulated in HIVpositive tumors (Figure 1a-e).

As DNMT dysregulation in cancer has been linked to dysregulation of miRNAs $[28,39,45,48,49]$, the expression of miRNAs known to directly regulate DNMTs was investigated. Six miRNAs (hsa-miR-130a, hsa-miR-130b, hsa-miR-148a, hsa-miR-148b, hsa-miR-152, hsa-miR301) have been reported to regulate the expression of DNMT1 [28], whereas the miR29 family and also hsa-

Table 4 Primer sequences for microRNA methylation analysis

\begin{tabular}{ll}
\hline microRNA & Primer sequence \\
\hline hsa-miR148a FORWARD (BSP) & 5'-TGGGTATTTTTITGTTGATTG-3' \\
hsa-miR148a REVERSE (BSP) & 5'ACTACACTTAAACCCCCTCTAACC-3' \\
hsa-miR152 FORWARD (BSP) & 5'-GGAATTTGTGTTATTTTGATTG-3' \\
hsa-miR152 REVERSE (BSP) & 5'CCAAACAAATATTCCACTACAAAC-3' \\
hsa-miR148a U-FORWARD (MSP) & 5'TTGATGTTTTAGTGTTTAGATGT-3' \\
hsa-miR148a U-REVERSE (MSP) & 5'AAAAAAATTAATCAAATTCCTCATA-3' \\
hsa-miR148a M-FORWARD (MSP) & 5'GTCGATGTCGTTAGTGTTTTAGAC-3' \\
hsa-miR148a M-REVERSE (MSP) & 5'AAAAAAATTAATCAAATTCCTCGTA-3'
\end{tabular}

hsa-miR148a hsa-miR148a (BSP) amplify a region of 326 bp; hsa-miR152 (BSP) amplify a region of $435 \mathrm{bp}$. Appropriate primers for MSP were found by the software only for hsa-miR148a, which amplify a region of $110 \mathrm{bp}$. 


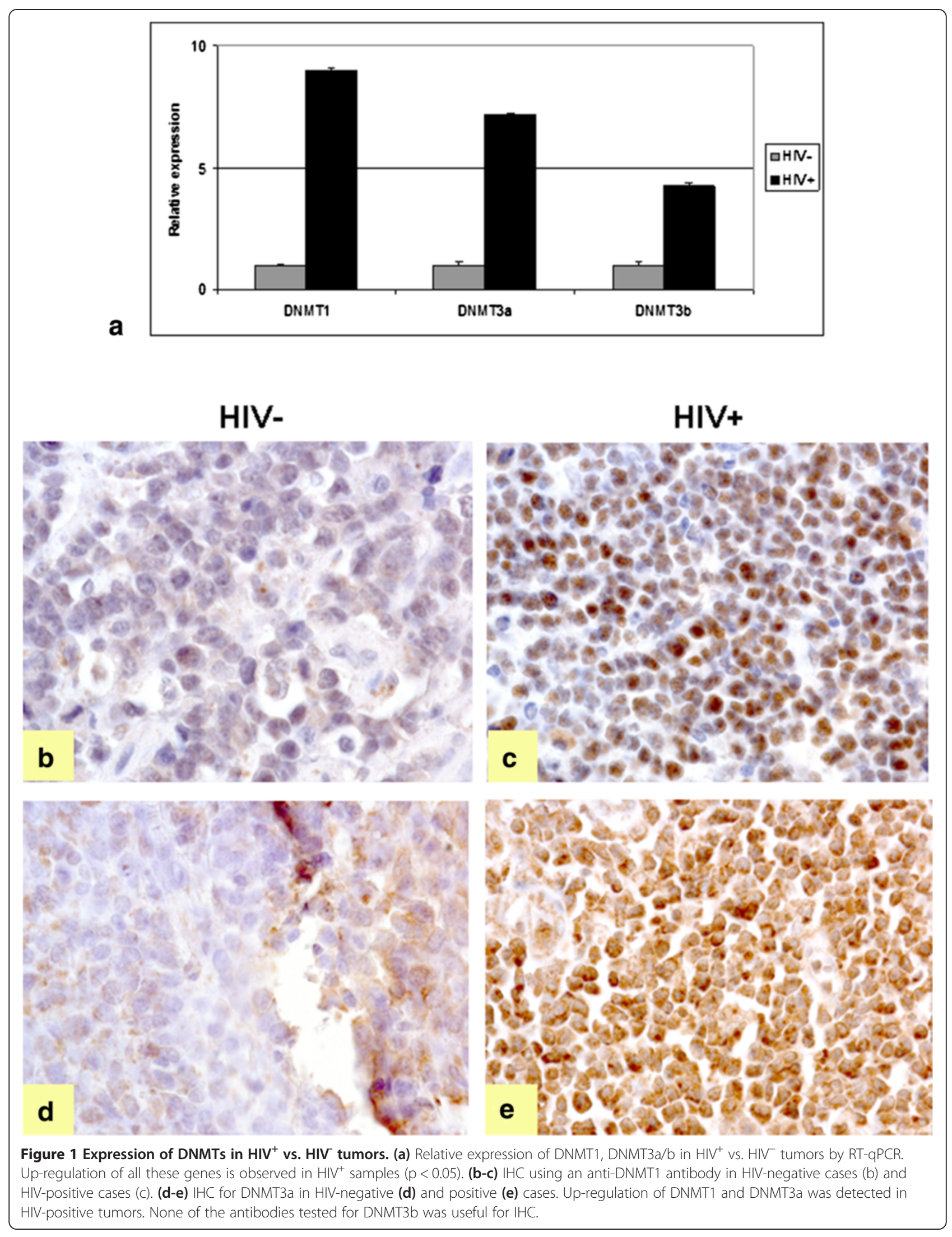




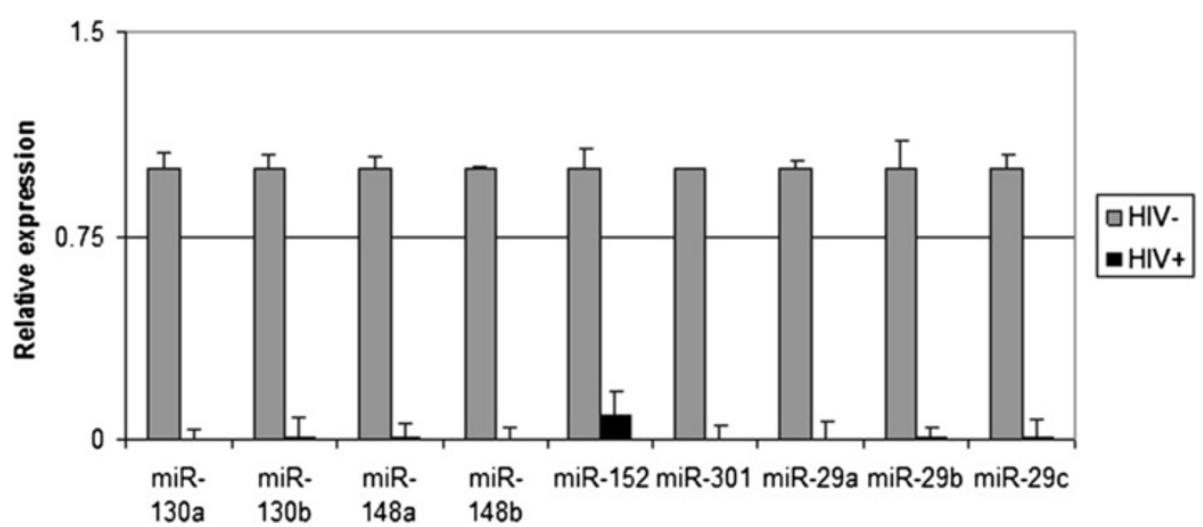

Figure 2 miRNAs predicted to regulate DNMT1, DNMT3a/b were analyzed by RT-qPCR in $\mathrm{HIV}^{+}$vs. $\mathrm{HIV}^{-}$primary tumors. A strong and significant down-regulation of all the selected miRNAs regulating DNMTs is observed in HIV-positive tumors $(p<0.05)$. The graph is representative of three different RT-qPCR experiments. Error bars represent standard deviation between duplicates.

miR148 regulate DNMT3 [45,46]. Our results demonstrate a marked down-regulation of all the selected DNMTregulating miRNAs in HIV-positive tumors (Figure 2), in respect with HIV-negative samples and normal lymph nodes.

\section{DNMT expression is increased in Tat-transfected cells}

We tested tumor tissues for the presence of HIV, which was confirmed in our series of cases by 24 staining by IHC (Figure 3a). Notably, HIV genome was not detected in tumor B-cells (data not shown), though they showed

a

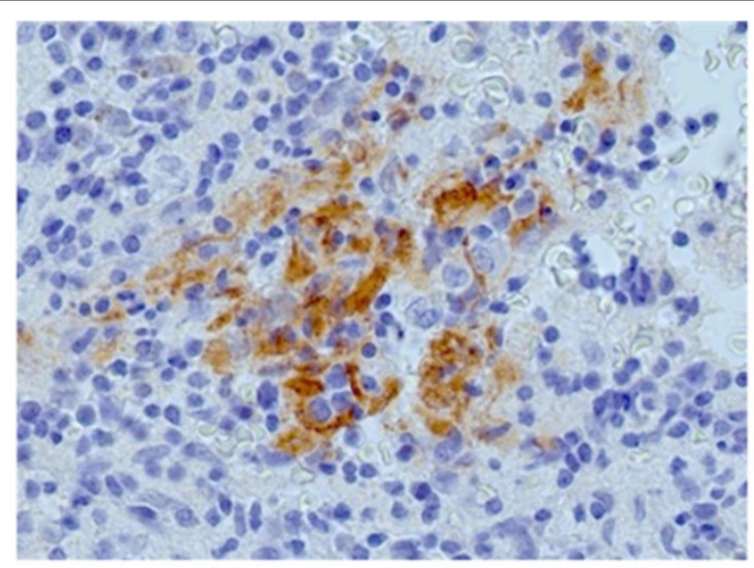

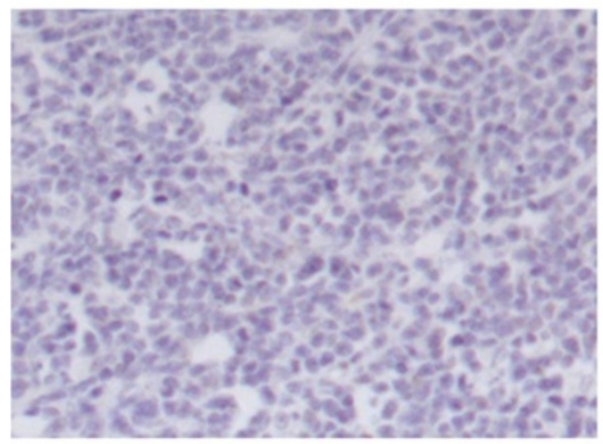

b
HIV-negative

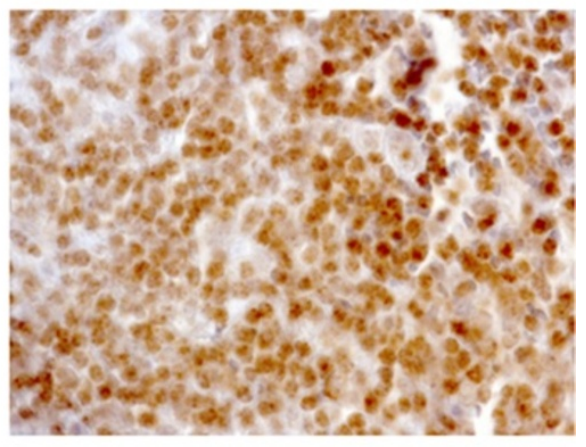

c
HIV-positive

Figure 3 Immunoistochemical staining for p24 and Tat in HIV $^{+}$vs. HIV tumors. (a) IHC using an anti-p24 antibody showed marked positivity of macrophages in a B-cell lymphoma of a HIV-positive subject. (b-c) IHC using an anti-Tat antibody in HIV-negative (b) and HIV-positive cases (c). Marked positivity to Tat of uninfected B-cells is visible in HIV-positive tumors, thus indicating that a soluble form of the protein is released from infected cells and enters neighbouring uninfected ones. 


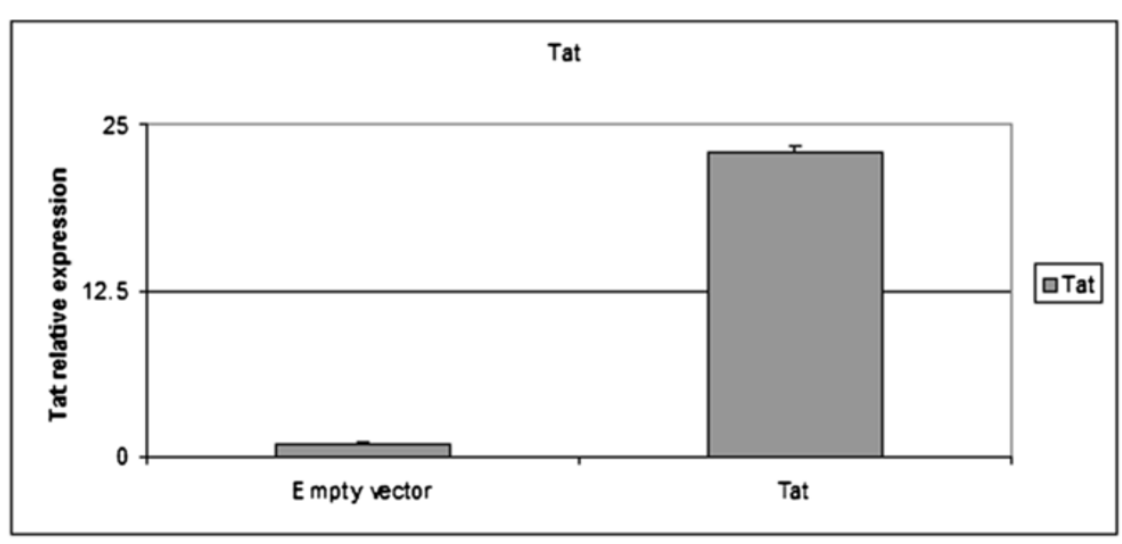

a

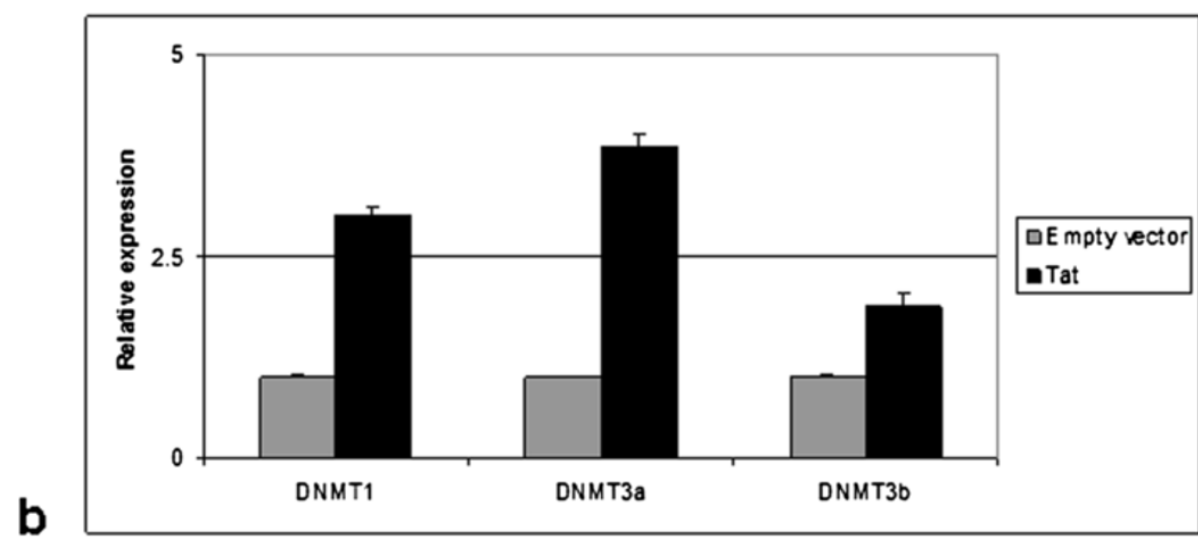

1

1.4

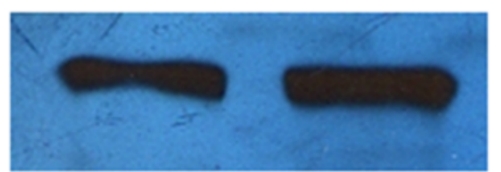

DNMT1

1

1,8

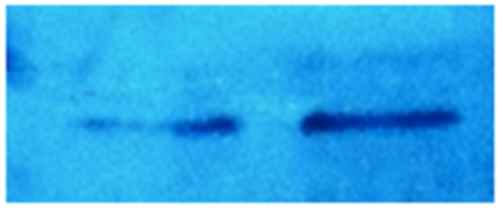

DNMT3a

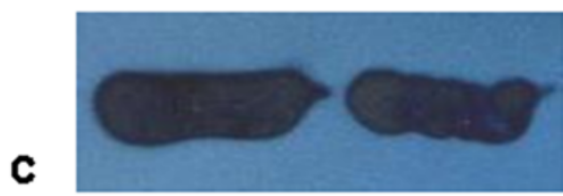

\section{Actin}

\section{Empty vector Tat}

Figure 4 DNMT expression in Tat-positive vs. Tat-negative cells. (a) Relative expression of Tat $24 \mathrm{~h}$ after transfection with a Tat-coding vector. (b-c) Ectopic expression of Tat was obtained either upon exposure to the recombinant protein or following transfection of a Tat-coding vector. DNMT1, DNMT3a/b expression was then analysed in Tat-positive (transfected or treated with soluble Tat) vs. Tat-negative cells (empty vector-transfected or untreated cells) at the mRNA level by RT-qPCR (b); up-regulation of all DNMTs is obtained following Tat ectopic expression, both upon exposure to recombinant Tat and following Tat-transfection $(\mathrm{p}<0.05)$. (c) Western blotting analysis for DNMT1 and DNMT3a in Tat-positive vs. Tat-negative cells. Up-regulation of both DNMTs is observed in Tat-positive cells, thus confirming results obtained in HIV-positive primary tumors. None of the tested antibodies for DNMT3b was suitable for WB analysis. Quantification by densitometric analysis is reported. 

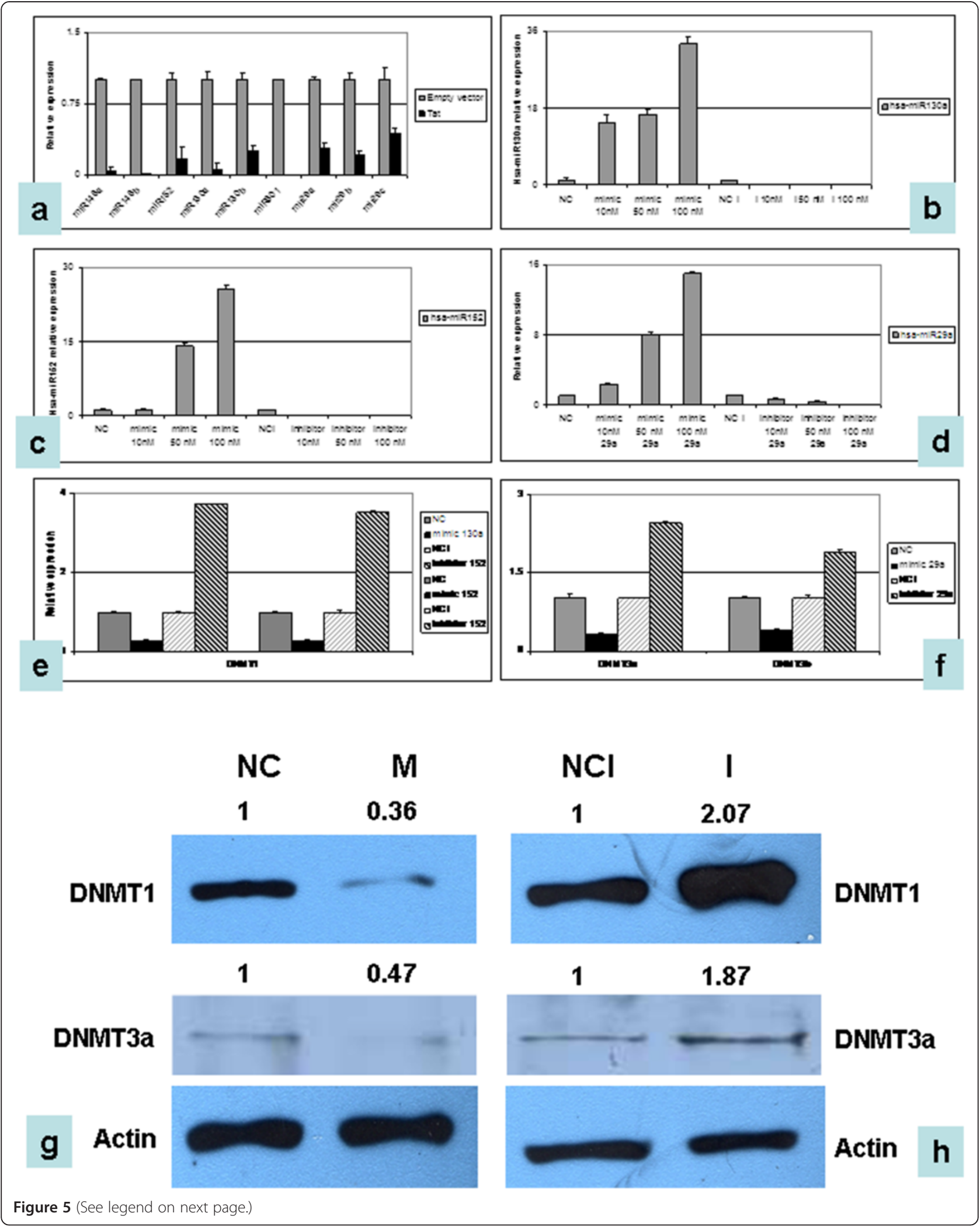
(See figure on previous page.)

Figure 5 Expression of DNMTs and DNMT-regulating miRNAs in Tat-positive vs. Tat-negative cells. DNMT1 and DNMT3a/b-regulating microRNA expression was checked by RT-qPCR in Tat-positive vs. Tat-negative cells following transient transfections and exposure to recombinant protein (a). Down-regulation of all miRNAs is observed in Tat-positive cells. The graph is representative of three different RT-qPCR experiments. Error bars represent standard deviation between duplicates. (b-d) Modulation of DNMT-regulating miRNAs was achieved by transient transfections of either mimics or antagomirs of the endogenous miRNAs at different concentration, and the effect on the expression of their respective miRNAs was monitored by RT-qPCR. DNMT1-regulating miRNAs (hsa-miR130a and hsa-miR152) are reported in (b-c), whereas DNMT3a/b regulating miRNAs (hsa-miR29) are shown in (d). (e-f) Relative expression of DNMT1 (e), DNMT3a/b (f) was then evaluated following the ectopic modulation of these miRNAs. Up-regulation of the specific miRNAs results in the down-regulation of DNMTs, whereas increased expression of DNMTs is observed following miRNA inhibition. The graph is representative of three different RT-qPCR experiments $(p<0.05)$. Error bars represent standard deviation between duplicates. (g-h): WB for DNMT1 and DNMT3a of cells transfected with hsa-miR152 (for DNMT1) and hsa-miR29 (for DNMT3a) mimics and inhibitors. NC: Mimic negative control; M: Either hsa-miR152 or hsa-miR29 mimic; NCl: Inhibitor negative control; l: Either hsa-miR152 or hsa-miR29 inhibitor. None of the tested antibodies for DNMT3b was suitable for WB analysis. Densitometric analysis results are reported.

positivity for Tat (Figure 3b-c). To test whether DNMT up-regulation in B-cells was possibly resulting from a soluble Tat released from infected cells and taken up by uninfected B-cells, we used an in vitro model of B-cell lymphoma in which Tat was ectopically expressed either by exposure to soluble Tat or by transient and stable transfections. Relative expression of DNMT1, DNMT3a/ b was then analyzed in our in vitro model by RT-qPCR and western blotting. Ectopic expression of Tat, either obtained by exposure to recombinant Tat or nucleofection, gave overlapping results, which showed that DNMTs are up-regulated following Tat ectopic expression, both at the mRNA and protein levels, as observed in primary tumors (Figure $4 \mathrm{a}-\mathrm{c}$ ).

\section{DNMT-regulating miRNAs are dysregulated in \\ Tat-transfected cell lines}

We then checked whether Tat-dependent up-regulation of DNMTs relied on miRNA down-regulation, as in HIV-positive primary tumors. Our results demonstrated that the ectopic expression of the Tat protein is sufficient per se to determine DNMT-controlling miRNA downregulation, both in transient (Figure 5a) and in stable Tat-transfected cells (data not shown). In addition, we used miRNA mimics and antagonists to modulate the expression of the endogenous miRNAs predicted to regulate DNMTs. Different concentrations for each mimic/antagonists were used, to assess the best dose-response effect (Figure 5b-d). The expression of DNMTs in cells transfected either with mimics or inhibitors was then checked, using mimics/inhibitors at the concentration proved to have the highest efficiency. Enhanced miRNA concentration resulted in decrease of DNMT1, DNMT3a/b whereas the inhibition of endogenous miRNAs resulted in their up-regulation, thus confirming regulation of DNMTs by the selected miRNAs in our cell model (Figure 5e-f). Western blotting confirmed modulation of DNMTs using mimics/inhibitors. In particular, ectopic over-expression of the selected miRNAs resulted in the down-regulation of DNMTs, whereas inhibition of the miRNA led to the consequent protein up-regulation (Figure 5g-h).

\section{Over-expression of DNMTs determines an increase of gene and microRNA methylation}

We have previously reported the physical interaction of Tat with the RB family of proteins, which results in the inactivation of their growth regulatory proteins [21,38]. Therefore, we monitored cell growth in Tat-transfected cells and observed an enhanced cell proliferation (Figure 6a), which may depend on Tat-mediated alteration of the G1/S transition of the cell cycle, through the physical interaction of Tat with the pocket proteins $[21,38,50]$. Notably, the expression of cyclin A, which is a specific S-phase marker, was higher in Tat-expressing cells, which is consistent with the enhanced proliferation rate in Tat-positive cells (Figure $6 \mathrm{~b}$ ). Subsequently, we checked the expression of RB1, INK4/p16 and TP53, crucial cell cycle regulators, in Tat-transfected cell lines. Our results demonstrate that the ectopic expression of Tat resulted in down-regulated expression of $I N K 4 / p 16$ and TP53, whereas no difference was instead observed for $R B 1$ (Figure $6 \mathrm{c}$ ). These in vitro results were then confirmed in HIV-positive primary tumors, by RT-qPCR (Figure 6d).

To verify whether down-regulation of $I N K 4 / p 16$ and TP53 was a consequence of promoter hypermethylation, DNA extracted from Tat-transfected cells and primary tumors was modified by bisulfite treatment, followed by MSP and BSP analyses. INK4/p16 was found hypermethylated both in Tat-transfected cells as well as in HIV-positive tumors, whereas no methylation was detected for TP53 (Figure 7a-b), whose down-regulation may possibly depend on genetic alterations. Decreased protein levels for p16 were also detected by IHC in HIVpositive primary tumors, in line with the INK4/p16 gene hypermethylation (Figure 7c). Hypermethylation was also checked for those miRNAs containing CpG islands. In particular, BSP and MSP analyses identified partial methylation for hsa-miR148a and hsa-miR152 (Figure 7d), 

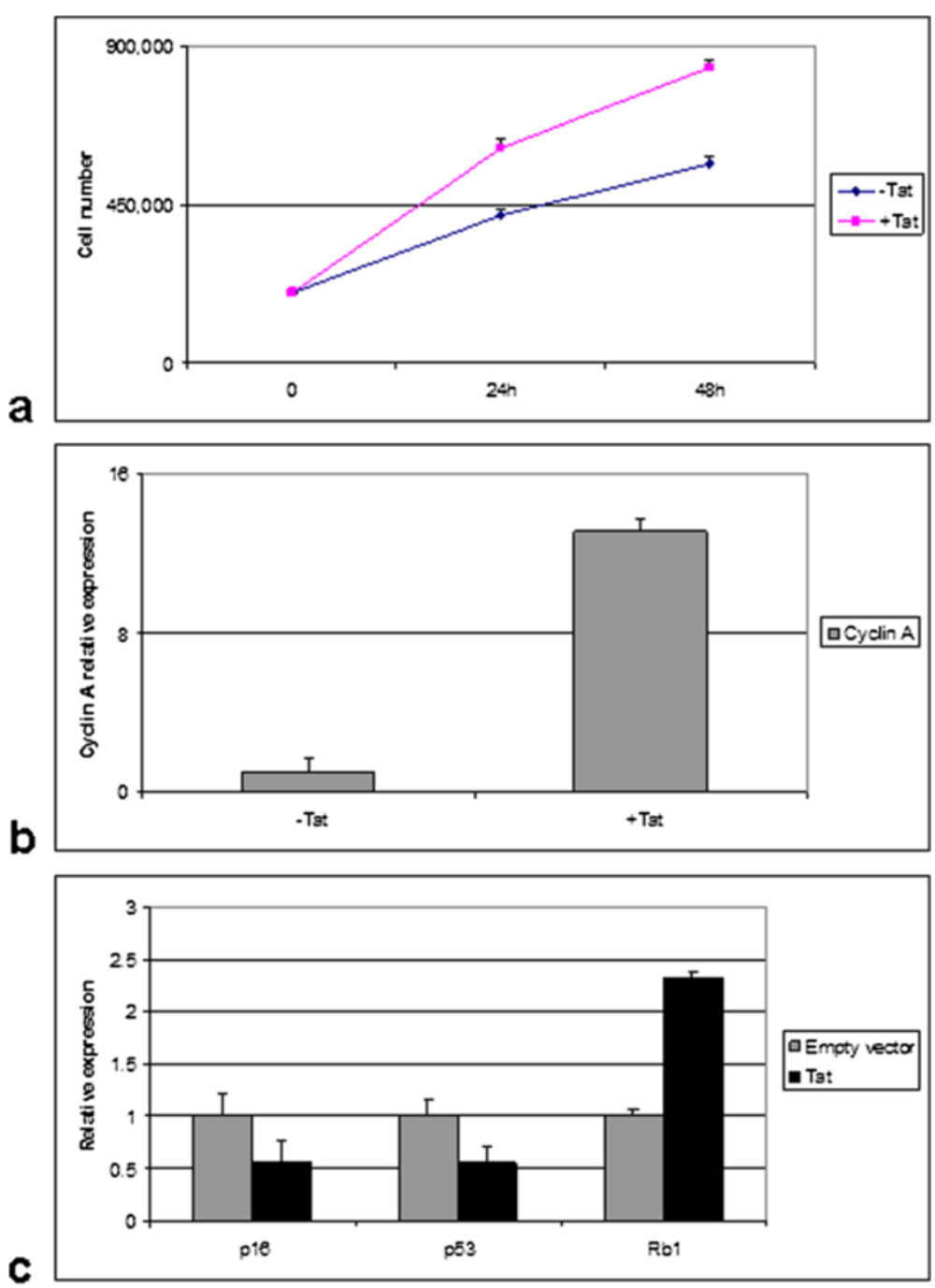

C

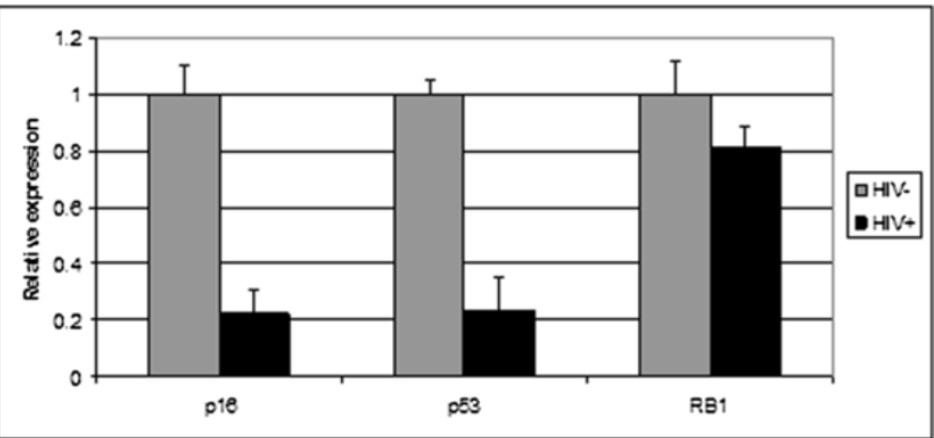

Figure 6 Analysis of cell cycle regulators in Tat-positive vs. Tat-negative cells. Cell proliferation in Tat-transfected vs. empty vector-transfected cells (a). Tat-transfected cells show a higher proliferation rate, which is in line with the increased expression of cyclin A (b), an S-phase specific marker. (c-d) Relative expression by RT-qPCR of INK4/p16, TP53 and RB1 in Tat-transfected cells (c) and in HIV-positive vs. HIV-negative primary tumors

(d). Down-regulation of INK4/P16 and TP53 is observed both in vitro and in vivo. The graph is representative of three different RT-qPCR experiments $(p<0.05)$. Error bars represent standard deviation between duplicates.

both in primary tumors and Tat-transfected cell lines (Table 5), whereas it was not possible to design appropriate primers for hsa-miR130a, due to the length of the product.
5-Aza treatment was then performed in Tat-transfected cell lines, to further confirm that miRNA down-regulation was dependent on hypermethylation. Following 5-Aza treatment, miRNA expression level was checked by RT- 

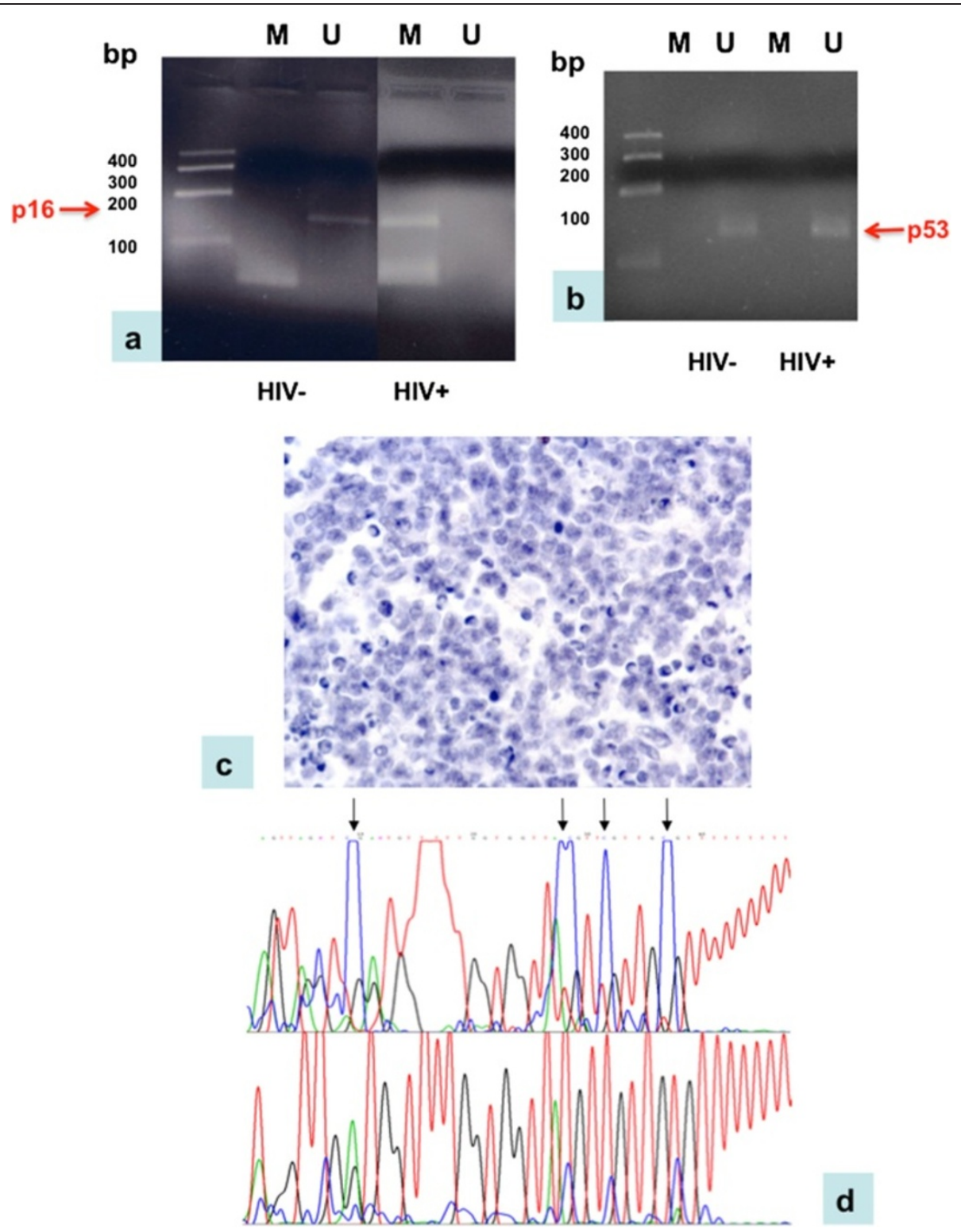

Figure 7 Methylation analysis of DNMT-dependent miRNAs and cell cycle regulatory genes in Tat-positive vs. Tat-negative cells and primary tumors. Methylation analysis of INK4/P16 (a) and TP53 (b) in HIV-positive and -negative primary tumors. M indicates the product using the methyled primers, $U$ indicates the product using the unmethyled primers. Amplification of INK4/p16 resulted in a band lower than 200 bp, whereas the specific product for TP53 was about $100 \mathrm{bp}$. The specific product for INK4/p16 was obtained only using unmethyled primers in HIV-negative samples, whereas only methyled primers resulted in a INK4/P16 product in HIV-positive tumors, which is indicative of INK4/p16 methylation in HIV-positive tumors. No differences were observed for TP53 between HIV-negative and HIV-positive tumors, as the amplified product was obtained only using unmethyled primers, indicating that no methylation is detectable for TP53 in neither of the two tumor types. Arrows indicate the presence of specific products for both genes. (c) $1 \mathrm{HC}$ for p16 in HIV-positive tumors; (d) Sequence analysis of hsa-miR-148a in HIV-positive and HIV-negative primary tumors. Arrows indicate the methyled C that are not converted to U in HIV-positive tumors.

qPCR. Our results demonstrated re-expression of miRNAs containing CpG islands (Figure 8a-b), whereas no change in the expression was instead observed for those miRNAs which do not contain CpG islands, as expected (Figure 8a-b). In addition, treatment with 5-Aza restored the expression of INK4/p16 in Tat-transfected cells, thus confirming silencing of the gene through hypermethylation in the presence of Tat (Figure 8c). To further confirm that down-regulation of INK4/p16 in the presence of Tat was due to miRNAs regulating DNMTs, we modulated the expression of the endogenous DNMTregulating miRNAs using synthetic mimics and antagomirs, and consequently evaluated the expression level of $I N K 4 / p 16$. Our results demonstrated that the expression 
Table 5 Analysis of methylated CpG sites for hsa-miR-148a and hsa-miR-152 in HIV-positive vs. negative primary tumors

\begin{tabular}{lll}
\hline & HIV $^{+}$ & HIV $^{\mathbf{H}}$ \\
\hline Hsa-miR-148a & & \\
Total CpG islands & 4 & 4 \\
Methylated CpG & 4 & 0 \\
Unmethylated CpG & 0 & 4 \\
Hsa-miR-152 & & \\
Total CpG islands & 30 & 30 \\
Methylated CpG & 25 & 11 \\
Unmethylated CpG & 5 & 19 \\
\hline
\end{tabular}

level of $I N K 4 / p 16$ varied according to the modulation of DNMT-regulating miRNAs. In particular, inhibition of the endogenous miRNAs, which determines DNMT overexpression, resulted in a decreased expression of INK4/ p16, which is consistent with DNMT-dependent hypermethylation. Conversely, ectopic up-regulation of the endogenous miRNAs using synthetic mimics led to the upregulation of $I N K 4 / p 16$, as a consequence of a reduced DNMT expression (Figure 8d).

As DNMT-mediated silencing of INK4/p16 through methylation may affect cell proliferation, due to the inactivation of its growth arrest properties, we monitored whether modulation of DNMT-regulating miRNAs through mimics/inhibitors may eventually affect cell growth. Our results show that inhibition of endogenous DNMT-regulating miRNAs through antagomirs results in an increased cell proliferation. Inhibition of endogenous miRNAs may affect cell proliferation through the upregulation of DNMTs and consequent silencing of INK4/ p16, which results in the abolishment of cell growth arrest. Conversely, DNMT down-regulation through miRNA mimics determines an opposite effect on cell growth (Figure 8e-f).

\section{Discussion}

Tumor viruses has been implicated in the etiology of many cancers including malignant mesotheliomas, nonHodgkin's lymphoma and tumors of the bone, brain and urinary tract [51-53]. The most commonly explored role for viruses in cancer involves the expression of viral oncogenes, such as polyomavirus large T-antigens (TAg), adenovirus E1a and E1b, and papillomavirus E6 and E7 [54]. These proteins share the ability to interact with and inactivate the pocket protein family $(\mathrm{pRb}, \mathrm{p} 107$, p130) and/or the p53 tumor suppressor [55-58]. This results in the activation of the cellular DNA replication machinery needed to replicate the viral genome and promotes increased cellular proliferation, delayed differentiation, and often malignant transformation [59].
HIV infection is often associated with the onset of malignant lymphomas, $95 \%$ of which are of B-cell origin. Some of them, as Burkitt lymphoma, may arise in immunocompetent patients, even before the AIDS manifestation. Due to the high $\mathrm{CD}_{4}^{+}$cell number of these patients, it is reasonable to hypothesize that malignant transformation in these cases may not be a consequence of the immunodepression of infected individuals, suggesting that HIV itself may be involved in driving the transformation process. The virus encodes for many proteins and viral microRNAs, using which it may compete with cellular proteins/RNAs, thus disturbing the physiological regulation of the host cell. As most transformed B-cells do not contain the virus, some other mechanisms and/or viral factors may be involved. Among these, the most reliable candidate is the Tat protein, as it may function as a soluble effector, being released from infected cells and taken up by uninfected B-cells, in a biologically active form. Our previous studies demonstrated that HIV-positive B-cell lymphomas may be positively stained by an anti-Tat antibody [21] and again here we show positivity for Tat in our set of B-cell tumors. Therefore the endocytosed Tat may directly exert its biological functions in uninfected B-cells.

The ability of Tat to act directly on B-cells and differentially modulate the B-cell response of naïve/memory and germinal center (GC) B-cells has been previously reported [19]. Tat-mediated induction of GC B-cell proliferation might therefore contribute to promote HIVassociated follicular hyperplasia, autoimmune disorders and B-cell malignancies. The effects of Tat are likely to impact on the early stages of the cell cycle, before the G1 to S phase transition, and on B-cell differentiation, rather than affecting isotype switching [19]. In addition, Tat has been shown to bind to the pocket proteins, thus interfering with control of cell growth $[21,38,50]$, which may eventually result in transformation.

However, while genetic perturbations have been shown to play key roles in viral transformation, epigenetic modifications such as DNA methylation may also play important roles during viral infection and transformation, as viral infection affects de novo methylation and transcription of cellular genes as well [60-62].

In this paper we have analyzed the expression of a particular class of proteins, the DNA Methyl Transferases, which epigenetically regulate gene expression, as HIV-1 has been reported to induce the expression of DNMT1 in vitro, which has a key role in the maintenance of DNA methylation, and epigenetically regulate the expression of several genes [29]. Over-expression of DNMT1 correlates with increased genomic methylation [30] and has been associated with miRNA dysregulation in liver cancer, in which DNMT1 over-expression is induced by IL-6 overproduction [28]. Here, we show that HIV enhances the 


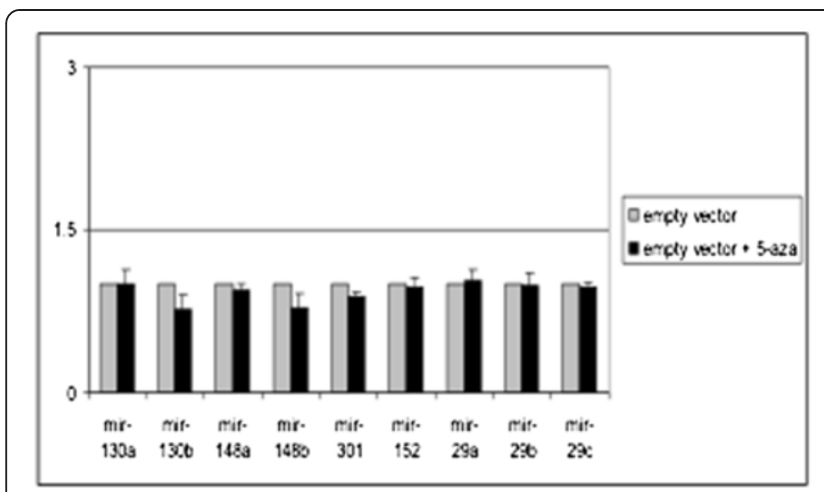

a

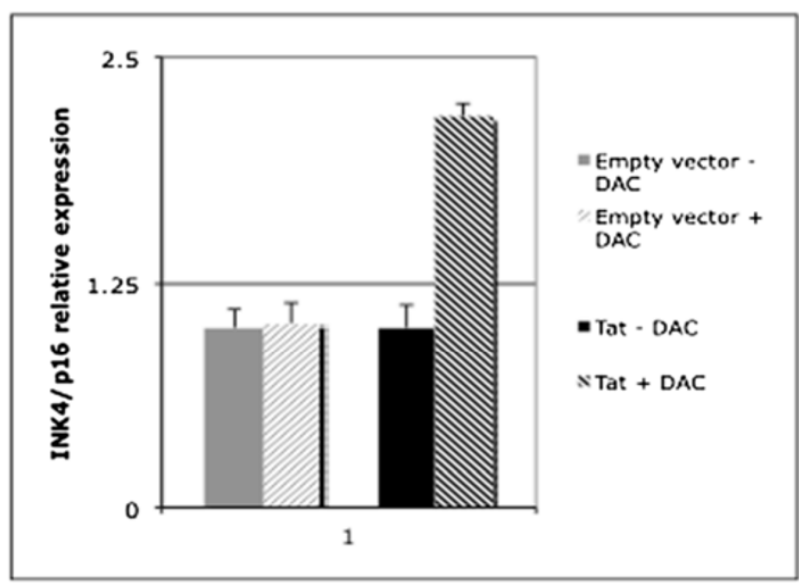

C

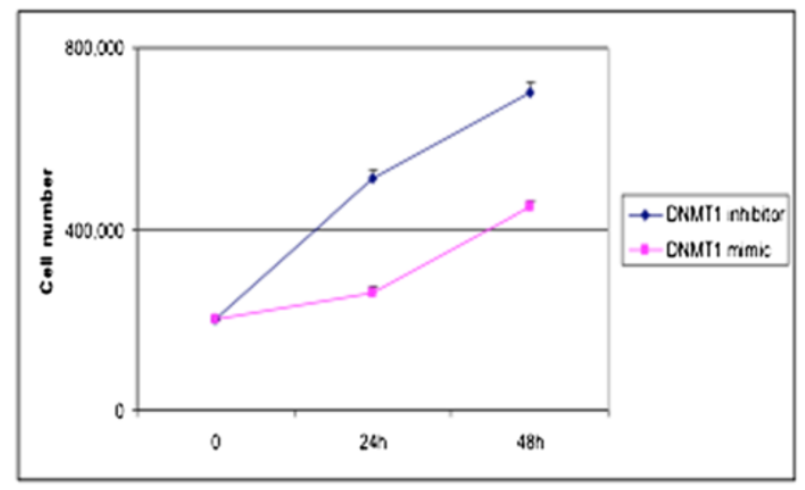

e

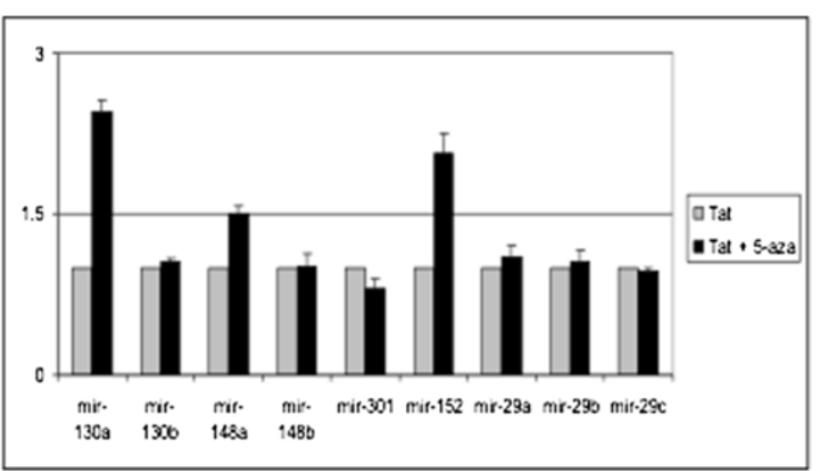

b

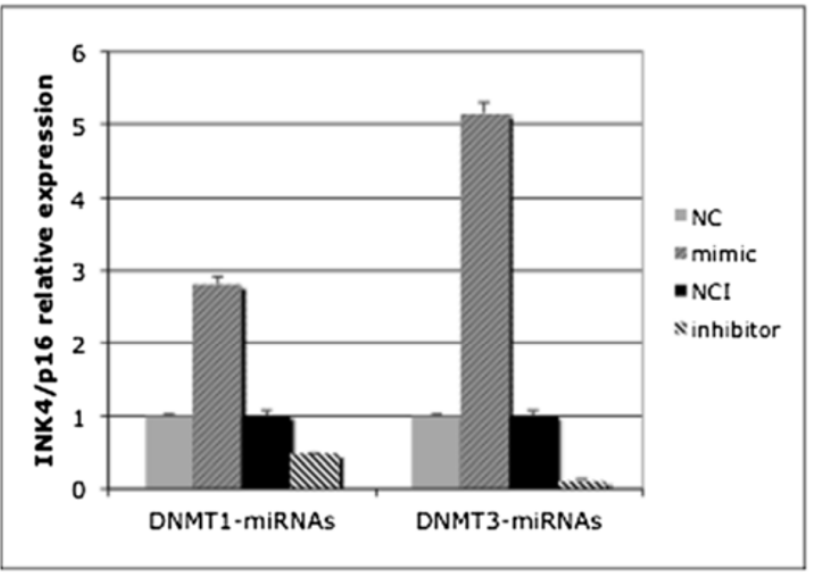

d

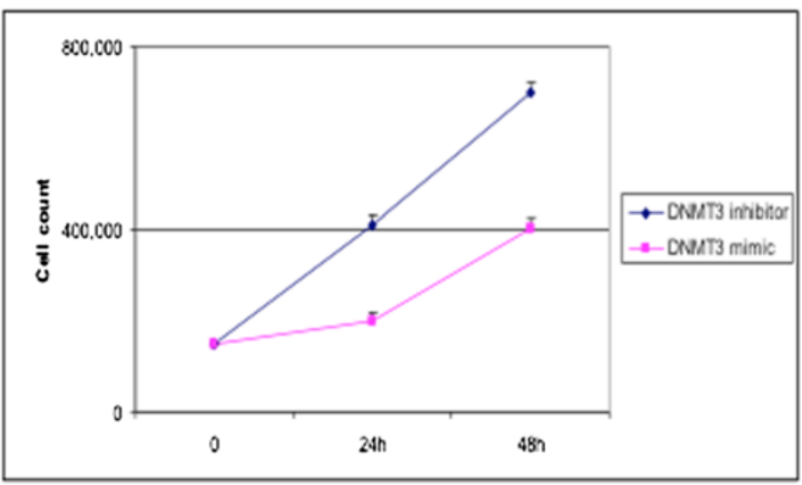

f

Figure $\mathbf{8}$ (See legend on next page.) 
(See figure on previous page.)

Figure 8 Modulation of DNMT-regulating miRNAs affects the expression of INK4/p16 and consequent cell growth control. Treatment with 5-Aza in (a) empty vector-transfected and (b) Tat-transfected cells. Treatment with 5-Aza induces the expression of miRNAs containing CpG islands in Tat-transfected cells, indicating that down-regulation of these miRNAs depends on hypermethylation. (c) Treatment with 5-Aza was also able to restore the expression of INK4/p16 in Tat-transfected cells, thus suggesting that silencing of INK4/p16 is due to hypermethylation. (d) Ectopic modulation of DNMT-regulating miRNAs was achieved using synthetic mimic or inhibitors. Relative expression of INK4/p16 was then checked by RT-qPCR. A decreased expression of the gene was observed following inhibition of miRNAs, which leads to up-regulation of DNMTs and consequent hypermethylation of target genes. Conversely, increased expression of endogenous miRNAs, which leads to downregulation of DNMTs, results in over-expression of INK4/p16 ( $p<0.05)$. NC: Mimic negative control; M: Either hsa-miR152 or hsa-miR29 mimic; NCl: Inhibitor negative control; l: Either hsa-miR152 or hsa-miR29 inhibitor. (e-f) Cell proliferation analysis in cells transfected with miRNA mimics/inhibitors for DNMT1 (e) and DNMT3a/b (f). Inhibition of the endogenous miRNAs enhances cell growth.

expression of DNMTs involved in both the basic and the de novo methylation. Such up-regulation relies on the down-regulation of specific miRNAs predicted to regulate DNMTs, in primary tumors of aggressive B-cell lymphomas, compared to HIV-negative tumors and normal tissues. The increased expression of DNMTs could result in an altered pattern of methylation of target genes/miRNAs in HIV-positive subjects. Noteworthy, reduction of the global methylation has been recently reported in HIVpositive subjects following HAART treatment [63], thus supporting the finding that HIV is able to increase global DNA methylation. As the HIV genome has not been detected in the tumor tissues of the aggressive B-cell lymphomas we analyzed, we hypothesized that Tat, released in a soluble form from infected cells, could contribute to malignant transformation of these cases. To test this hypothesis, we used an in vitro model obtained by ectopic expression of Tat in B-cells, either by cell transfections or exposure to recombinant Tat. In line with our in vivo results, we observed that the ectopic expression of Tat was able to induce overexpression of DNMTs based on downregulation of DNMT-regulating miRNAs, pointing at a direct role for Tat in regulating DNMT expression.

Based on the growth capability acquired by Tattransfected cells, which may depend on silencing of cell cycle progression inhibitory genes, we have then analyzed whether key cell cycle regulatory genes, as INK4/ p16, TP53 and RB1, may be possibly silenced through methylation, thus leading to the loss of the G1/S control [50], in Tat-transfected cells. Our results demonstrate a down-regulated expression of $I N K 4 / p 16$ and TP53, in Tat-transfected cells, whereas no difference is observed for RB1. In addition, we show that the reduced expression of $I N K 4 / p 16$, following ectopic expression of Tat, was specifically due to hypermethylation, whereas no methylation was detected for TP53. 5-aza-2-deoxycitidine
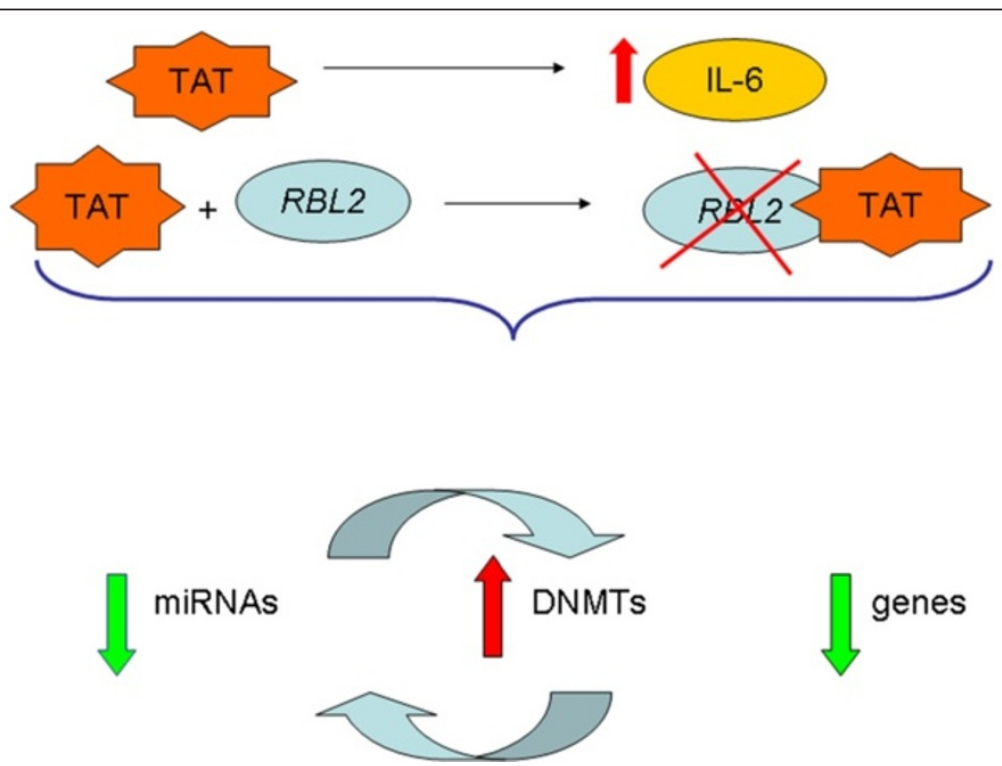

genes

Figure 9 A model for Tat-mediated lymphomagenesis. DNMT aberrant activity may be induced by both IL-6 and RB-protein inactivation. As Tat is able to induce both IL-6 expression and RBL2-gene product inactivation, we hypothesize that Tat may induce DNMT up-regulation through these mechanisms, which results in the aberrant methylation of genes and miRNAs. 
treatment restored the expression of down-regulated miRNAs, for which CpG islands have been described, thus suggesting that miRNA down-regulation Tat-transfected cell lines may depend on hypermethylation resulting from aberrant DNMT expression. The in vitro results were then confirmed in HIV-positive primary tumors. Interestingly, cell growth was affected by transfections of mimics/inhibitors, as inhibition of the endogenous miRNAs resulted in a higher proliferation rate. This may be due to the upregulation of DNMTs and consequent INK4/p16 silencing through methylation, which removes the control on cell growth and speeds up cell proliferation.

Transcriptional inactivation of DNMTs has been recently reported to occur by $\mathrm{Rb}$ proteins and this effect was shown to be reversible by Rb-inactivating viral oncoproteins such as the T-antigen [32-36]. In particular, decreased DNMT expression has been linked to the activity of the $R B L 2$ gene product [37]. Notably, we have previously demonstrated that Tat is able to inactivate RBL2/ p130 through a physical binding $[21,38]$. This may represent an intriguing mechanism through which Tat upregulates DNMT expression in B-cells of infected patients by inactivating $R B L 2$ activity.

As Tat is also able to induce the expression of IL-6, which in turn determines aberrant DNMT1 activity, we may propose a model for Tat-mediated transformation in B-cells of HIV-infected patients, who have high levels of IL-6 (Figure 9). It is reasonable to hypothesize that a soluble form of Tat, released from infected cells within the B-cell tumor, is taken by uninfected B-cells. This biologically active Tat is now able to modulate the expression of several genes, including IL-6 [25]. The over-production of IL-6, together with the Tat-mediated inactivation of $R B L 2$, could be then responsible for the up-regulated expression of DNMTs, which determines an aberrant methylation pattern of genes/microRNAs. Among these, hypermethylation of INK4/p16 may be crucial, as its silencing would lead to the loss of control on a key cell cycle restriction point, as suggested by an enhanced cell proliferation, which may then confer cells a growth advantage and eventually result in malignant transformation.

\section{Conclusions}

The Tat-dependent modulation of DNA Methyl Transferases provides an attractive mechanism through which it can restore and maintain methylation of critical genes in HIV-infected individuals.

\section{Competing interests}

The authors declare that they have no competing interests.

\section{Authors' contributions}

$A L, F M, S G, L M, A O$, SM performed the experiments; $C B, L L$ and EAR analyzed the cases; EAR contributed reagents/materials/analysis tool; GDF conceived, designed the experiments and wrote the paper. All authors read and approved the final manuscript.

\section{Acknowledgements}

This work has been supported by the "Progetto Salute Regione Toscana" grant.

\section{Author details}

${ }^{1}$ Department of Medical Biotechnologies, University of Siena, Siena, Italy. ${ }^{2}$ Department of Pathology, University of Nairobi, Nairobi, Kenya. ${ }^{3}$ School of Biological and Chemical Sciences, Queen Mary University of London, London, UK

Received: 25 August 2014 Accepted: 14 November 2014

Published: 9 December 2014

\section{References}

1. World Health Organization Classification of Tumours: Tumours of Haematopoietic and Lymphoid tissues. Edited by Jaffe ES, Harris NL, Stein H, Vardimar JW. Lyon: IARC Press; 2008.

2. Moir S, Fauci A: Pathogenic mechanisms of B-lymphocyte dysfunction in HIV disease. J Allergy Clin Immunol 2008, 122:12-19. quiz 20-1.

3. Moir S, Malaspina A, Ogwaro KM, Donoghue ET, Hallahan CW, Ehler LA, Liu S, Adelsberger J, Lapointe R, Hwu P, Baseler M, Orenstein JM, Chun TW, Mican JA, Fauci AS: HIV-1 induces phenotypic and functional perturbations of B cells in chronically infected individuals. Proc Natl Acad Sci 2001, 98:10362-10367.

4. Moir S, Malaspina A, Pickeral OK, Donoghue ET, Vasquez J, Miller NJ, Krishnan SR, Planta MA, Turney JF, Justement JS, Kottilil S, Dybul M, Mican JM, Kovacs C, Chun TW, Birse CE, Fauci AS: Decreased survival of B cells of HIV-viremic patients mediated by altered expression of receptors of the TNF superfamily. J Exp Med 2004, 200:587-599.

5. Titanji K, De Milito A, Cagigi A, Thorstensson R, Grützmeier S, Atlas A, Hejdeman B, Kroon FP, Lopalco L, Nilsson A, Chiodi F: Loss of memory B cells impairs maintenance of long-term serologic memory during HIV-1 infection. Blood 2006, 108:1580-1587.

6. Malaspina A, Moir S, Ho J, Wang W, Howell ML, O'Shea MA, Roby GA, Rehm CA, Mican JM, Chun TW, Fauci AS: Appearance of immature/transitional B cells in HIV-infected individuals with advanced disease: correlation with increased IL-7. Proc Natl Acad Sci 2006, 103:2262-2267.

7. Malaspina A, Moir S, Chaitt DG, Rehm CA, Kottilil S, Falloon J, Fauci AS: Idiopathic $\mathrm{CD}^{+} \mathrm{T}$ lymphocytopenia is associated with increases in immature/transitional B cells and serum levels of IL-7. Blood 2007 109:2086-2088.

8. Richard Y, Amiel C, Jeantils V, Mestivier D, Portier A, Dhello G, Feuillard J, Creidy R, Nicolas JC, Raphael M: Changes in blood B-cell phenotypes and Epstein-Barr virus load in chronically human immunodeficiency virus-infected patients before and after antiretroviral therapy. J Inf Dis 2010, 202:1424-1434.

9. Neri A, Barriga F, Knowles DM, Magrath IT, Dalla-Favera R: Different regions of the immunoglobulin heavy-chain locus are involved in chromosomal translocations in distinct pathogenetic forms of Burkitt lymphoma. Proc Natl Acad Sci 1988, 85:2448-2452.

10. Beckhardt RN, Farady N, May M, Torres RA, Strauchen JA: Increased incidence of malignant lymphoma in AIDS: a comparison of risk groups and possible etiologic factors. Mt Sinai J Med 1988, 55:383-389.

11. Cheng SM, Li JCB, Lin SS, Lee DCW, Liu L, Chen Z, Allan S: HIV-1 transactivator protein induction of suppressor of cytokine signaling-2 contributes to dysregulation of IFNy signaling. Blood 2009, 113:5192-5201.

12. Shearer GM: HIV-induced immunopathogenesis. Immunity 1998, 9:587-593.

13. Kaul D, Ahlawat A, Dutta Gupta S: HIV-1 genome-encoded HIV1-miR-H1 impairs cellular responses to infection. Mol Cell Biochem 2009, 323:143-148.

14. Marzio G, Tyagi M, Gutierrez MI, Giacca M: HIV-1 tat transactivator recruits p300 and CREB-binding protein histone acetyltransferases to the viral promoter. Proc Natl Acad Sci 1998, 95:13519-13524.

15. Rana TM, Jeang KT: Biochemical and functional interactions between HIV-1 Tat protein and TAR RNA. Arch Biochem Biophys 1999, 365:175-185.

16. Furia B, Deng L, Wu K, Baylor S, Kehn K, Li H, Donnelly R, Coleman T, Kashanchi F: Enhancement of nuclear factor-kappa B acetylation by coactivator p300 and HIV-1 Tat proteins. J Biol Chem 2002, 277:4973-4980.

17. Frankel $A D$, Pabo $C O$ : Cellular uptake of the tat protein from human immunodeficiency virus. Cell 1988, 55:1189-1193.

18. Tyagi M, Rusnati M, Presta M, Giacca M: Internalization of HIV-1 tat requires cell surface heparan sulfate proteoglycans. J Biol Chem 2001, 276:3254-3261. 
19. Lefevre EA, Krzysiek R, Loret EP, Galanaud P, Richard Y: Cutting edge: HIV-1 Tat protein differentially modulates the $B$ cell response of naive, memory, and germinal center B cells. J Immunol 1999, 163:1119-1122.

20. Frankel AD, Biancalana $S$, Hudson D: Activity of synthetic peptides from the Tat protein of human immunodeficiency virus type 1. Proc Natl Acad Sci 1989, 86:7397-7401

21. Lazzi S, Bellan C, De Falco G, Cinti C, Ferrari F, Nyongo A, Claudio PP, Tosi GM, Vatti R, Gloghini A, Carbone A, Giordano A, Leoncini L, Tosi P: Expression of RB2/p130 tumor-suppressor gene in AIDS-related non-Hodgkin's lymphomas: implications for disease pathogenesis. Hum Pathol 2002, 33:723-731

22. Sharma V, Knoblock TJ, Benjamin D: Differential expression of cytokine genes in HIV-1 tat transfected T and B cell lines. Biochem Biophys Res Comm 1995, 208:704-713.

23. de Paulis A, De Palma R, Di Gioia L, Carfora M, Prevete N, Tosi G, Accolla RS, Marone G: Tat protein is an HIV-1-encoded beta-chemokine homolog that promotes migration and up-regulates CCR3 expression on human Fc epsilon $\mathrm{RI}^{+}$cells. J Immunol 2000, 165:7171-7179.

24. McManus CM, Weidenheim K, Woodman SE, Nunez J, Hesselgesser J, Nath A, Berman JW: Chemokine and chemokine-receptor expression in human glial elements: induction by the HIV protein, Tat, and chemokine autoregulation. Am J Pathol 2000, 156:1441-1453.

25. Scala G, Ruocco MR, Ambrosino C, Mallardo M, Giordano V, Baldassarre F, Dragonetti E, Quinto I, Venuta S: The expression of the interleukin 6 gene is induced by the human immunodeficiency virus 1 TAT protein. J Exp Med 1994, 179:961-971.

26. Blazevic V, Heino M, Lagerstedt A, Ranki A, Krohn KJ: Interleukin-10 gene expression induced by HIV-1 Tat and Rev in the cells of HIV-1 infected individuals. J Acquired Immunedefic Syndr Hum Retrovir 1996, 13:208-214.

27. Kundu RK, Sangiorgi F, Wu LY, Pattengale PK, Hinton DR, Gill PS, Maxson R: Expression of the human immunodeficiency virus-Tat gene in lymphoid tissues of transgenic mice is associated with B-cell lymphoma. Blood 1999, 94:275-282.

28. Braconi C, Huang N, Patel T: MicroRNA-dependent regulation of DNA methyltransferase-1 and tumor suppressor gene expression by interleukin6 in human malignant cholangiocytes. Hepatology 2010, 51:881-890.

29. Fang JY, Mikovits JA, Bagni R, Petrow-Sadowski CL, Ruscetti FW: Infection of lymphoid cells by integration-defective human immunodeficiency virus type 1 increases de novo methylation. J Virol 2001, 75:9753-9961.

30. Youngblood B, Reich NO: The early expressed HIV-1 genes regulate DNMT1 expression. Epigenetics 2008, 3:149-156.

31. Breen EC, van der Meijden M, Cumberland W, Kishimoto T, Detels R, Martínez-Maza O: The development of AIDS-associated Burkitt's/small noncleaved cell lymphoma is preceded by elevated serum levels of interleukin 6. Clin Immunol 1999, 92:293-299.

32. McCabe MT, Low JA, Imperiale MJ, Day ML: Human polyomavirus BKV transcriptionally activates DNA methyltransferase 1 through the $\mathrm{pRb} / \mathrm{E} 2 \mathrm{~F}$ pathway. Oncogene 2006, 25:2727-2735.

33. McCabe MT, Low JA, Daignault S, Imperiale MJ, Wojno KJ, Day ML: Inhibition of DNA methyltransferase activity prevents tumorigenesis in a mouse model of prostate cancer. Cancer Res 2006, 66:385-392.

34. McCabe MT, Davis JN, Day ML: Regulation of DNA methyltransferase 1 by the pRb/E2F1 pathway. Cancer Res 2005, 65:3624-3632.

35. Kimura H, Nakamura T, Ogawa T, Tanaka S, Shiota K: Transcription of mouse DNA methyltransferase 1 (Dnmt1) is regulated by both E2F-Rb-HDACdependent and -independent pathways. Nucleic Acids Res 2003, 31:3101-3113.

36. Pradhan S, Kim GD: The retinoblastoma gene product interacts with maintenance human DNA (cytosine-5) methyltransferase and modulates its activity. EMBO J 2002, 21:779-788.

37. Benetti R, Gonzalo S, Jaco I, Muñoz P, Gonzalez S, Schoeftner S, Murchison E, Andl T, Chen T, Klatt P, Li E, Serrano M, Millar S, Hannon G, Blasco MA: A mammalian microRNA cluster controls DNA methylation and telomere recombination via Rbl2-dependent regulation of DNA methyltransferases. Nat Struct Mol Biol 2008, 15:998

38. De Falco G, Bellan C, Lazzi S, Claudio PP, La Sala D, Cinti C, Tosi P, Giordano A, Leoncini L: Interaction between HIV-1 Tat and pRb2/p130: a possible mechanism in the pathogenesis of AIDS-related neoplasms. Oncogene 2003, 22:6214-6219.

39. Huang J, Wang Y, Guo Y, Sun S: Down-regulated microRNA-152 induces aberrant DNA methylation in hepatitis $B$ virus-related hepatocellular carcinoma by targeting DNA methyltransferase 1. Hepatology 2010, 52:60-70.
40. De Falco G, Leucci E, Lenze D, Piccaluga PP, Claudio PP, Onnis A, Cerino G, Nyagol J, Mwanda W, Bellan C, Hummel M, Pileri S, Tosi P, Stein H, Giordano A, Leoncini L: Gene expression analysis identifies novel RBL2/p130 target genes in endemic Burkitt's lymphoma cell lines and primary tumors. Blood 2007, 110:1301-1307.

41. Onnis A, De Falco G, Antonicelli G, Onorati M, Bellan C, Sherman O, Sayed S, Lorenzo Leoncini L: Alteration of MicroRNAs regulated by c-Myc in Burkitt lymphoma. PloS One 2010, 5(9):e12960.

42. Lazzi S, Ferrari F, Nyongo A, Palummo N, de Milito A, Zazzi M, Leoncini L, Luzi P, Tosi P: HIV-associated malignant lymphomas in Kenya (Equatorial Africa). Hum Pathol 1998, 29:1285-1289.

43. Sethupathy P, Corda B, Hatzigeorgiou AG: TarBase: a comprehensive database of experimentally supported animal microRNA targets. RNA 2006, 12:192-197.

44. Ambros V, Bartel B, Bartel DP, Burge CB, Carrington JC, Chen X, Dreyfuss G, Eddy SR, Griffiths-Jones S, Marshall M, Matzke M, Ruvkun G, Tuschl T: A uniform system for microRNA annotation. RNA 2003, 9:277-279.

45. Fabbri M, Garzon R, Cimmino A, Liu Z, Zanesi N, Callegari E, Liu S, Alder H, Costinean S, Fernandez-Cymering C, Volinia S, Guler G, Morrison CD, Chan KK, Marcucci G, Calin GA, Huebner K, Croce CM: MicroRNA-29 family reverts aberrant methylation in lung cancer by targeting DNA methyltransferases3A and 3B Proc. Natl Acad Sci U S A 2007, 104:15805-15810.

46. Duursma M, Kedde M, Schrier M, le Sage C, Agami R: miR-148 targets human DNMT3b protein coding region. RNA 2008, 14:872-877.

47. Livak KJ, Schmittgen TD: Analysis of relative gene expression data using real-time quantitative PCR and the 2(-Delta Delta $C(T)$ ) method. Methods 2001, 25:402-408.

48. Gailhouste L, Gomez-Santos L, Hagiwara K, Hatada I, Kitagawa N, Kawaharada K, Thirion M, Kosaka N, Takahashi RU, Shibata T, Miyajima A, Ochiya T: miR-148a plays a pivotal role in the liver by promoting the hepatospecific phenotype and suppressing the invasiveness of transformed cells. Hepatology 2013, 58:1153-1165.

49. Anwar SL, Albat C, Krech T, Hasemeier B, Schipper E, Schweitzer N, Vogel A Kreipe H, Lehmann U: Concordant hypermethylation of intergenic microRNA genes in human hepatocellular carcinoma as new diagnostic and prognostic marker. Int J Cancer 2013, 133:660-670.

50. Nyagol J, Leucci E, Onnis A, De Falco G, Tigli C, Sanseverino F, Torricelli M, Palummo N, Pacenti L, Santopietro R, Spina D, Gichangi P, Muchiri L, Lazzi S, Petraglia F, Leoncini L, Giordano A: The effects of HIV-1 Tat protein on cell cycle during cervical carcinogenesis. Cancer Biol Ther 2006, 5:684-690.

51. Khalili K, Del Valle L, Otte J, Weaver M, Gordon J: Human neurotropic polyomavirus, JCV, and its role in carcinogenesis. Oncogene 2003, 22:5181-5191.

52. Tognon M, Corallini A, Martini F, Negrini M, Barbanti-Brodano G: Oncogenic transformation by BK virus and association with human tumors. Oncogene 2003, 22:5192-5200.

53. Vilchez RA, Butel JS: Emergent human pathogen simian virus 40 and its role in cancer. Clin Microbiol Rev 2004, 17:495-508.

54. O'Shea CC: DNA tumor viruses - the spies who lyse us. Curr Opin Genet Dev 2005, 15:18-26.

55. DeCaprio JA, Ludlow JW, Figge J, Shew JY, Huang CM, Lee WH, Marsilio E, Paucha E, Livingston DM: SV40 large tumor antigen forms a specific complex with the product of the retinoblastoma susceptibility gene. Cell 1988, 54:275-283.

56. Nakshatri $H$, Pater MM, Pater A: Functional role of BK virus tumor antigens in transformation. J Virol 1988, 62:4613-4621.

57. Bollag B, Chuke WF, Frisque RJ: Hybrid genomes of the polyomaviruses JC virus, $B K$ virus, and simian virus 40 : identification of sequences important for efficient transformation. J Virol 1989, 63:863-872.

58. Harris KF, Christensen JB, Imperiale MJ: BK virus large T antigen: interactions with the retinoblastoma family of tumor suppressor proteins and effects on cellular growth control. J Virol 1996, 70:2378-2386.

59. Syrjänen SM, Syrjänen KJ: New concepts on the role of human papillomavirus in cell cycle regulation. Ann Med 1999, 31:175-187.

60. Heller H, Kämmer C, Wilgenbus P, Doerfler W: Chromosomal insertion of foreign (adenovirus type 12, plasmid, or bacteriophage lambda) DNA is associated with enhanced methylation of cellular DNA segments. Proc Natl Acad Sci U S A 1995, 92:5515-5519.

61. Remus R, Kämmer C, Heller H, Schmitz B, Schell G, Doerfler W: Insertion of foreign DNA into an established mammalian genome can alter the methylation of cellular DNA sequences. J Virol 1999, 73:1010-1022. 
62. Hohlweg U, Hösel M, Dorn A, Webb D, Hilger-Eversheim K, Remus R, Schmitz B, Buettner R, Schramme A, Corzilius L, Niemann A, Doerfler W: Intraperitoneal dissemination of Ad12-induced undifferentiated neuroectodermal hamster tumors: de novo methylation and transcription patterns of integrated viral and of cellular genes. Virus Res 2003, 98:45-56.

63. Ghosh SK, McCormick TS, Eapen BL, Yohannes E, Chance MR, Weinberg A: Comparison of epigenetic profiles of human oral epithelial cells from HIV-positive (on HAART) and HIV-negative subjects. Epigenetics 2013, 8:703-709.

doi:10.1186/1750-9378-9-41

Cite this article as: Luzzi et al: HIV-1 Tat induces DNMT over-expression through microRNA dysregulation in HIV-related non Hodgkin lymphomas. Infectious Agents and Cancer 2014 9:41.

\section{Submit your next manuscript to BioMed Central and take full advantage of:}

- Convenient online submission

- Thorough peer review

- No space constraints or color figure charges

- Immediate publication on acceptance

- Inclusion in PubMed, CAS, Scopus and Google Scholar

- Research which is freely available for redistribution 